\title{
Functionalization of Graphene Oxide with 9-aminoanthracene for the Adsorptive Removal of Persistent Aromatic Pollutants from Aqueous Solution
}

\author{
Ali Balati, ${ }^{1}$ Mohammad Ghanbari, ${ }^{2}$ Sara Karimi Behzad ${ }^{3}$ \\ and Mostafa M. Amini*,3 \\ ${ }^{1}$ Environmental Sciences Research Institute, Shahid Beheshti University, G.C., Tehran 1983963113, Iran \\ ${ }^{2}$ Department of Organic Chemistry, Faculty of Chemistry, University of Kashan, Kashan, Iran. \\ ${ }^{3}$ Department of Chemistry, Shahid Beheshti University, G.C., Tehran 1983963113, Iran \\ * Corresponding author: E-mail: m-pouramini@sbu.ac.ir \\ Tel: +98-21-29903109; fax: +9-21-22431663
}

Received: 17-03-2017

\begin{abstract}
A novel modified graphene oxide nanocomposite was fabricated via a facial procedure, aiming to removal of the aromatic pollutants from aqueous solution. The graphene oxide (GO) was functionalized with 9-aminoanthracene and produced graphene oxide-9-aminoanthracene (GO-9-AA). FTIR, XRD, TGA, TEM and Raman spectroscopy techniques were used for characterization of the adsorbents. Adsorption of naphthalene (NAP), acenaphthylene (ACN), and phenanthrene (PHN) as a model of polycyclic aromatic hydrocarbons (PAHs) was investigated by GO-9-AA. The adsorbent showed excellent removal efficiency towards PAHs from aqueous solution. Equilibrium data of the adsorption process were successfully fitted with Freundlich model from single solute system, and the maximum adsorption capacities followed the order of NAP $>$ ACN $>$ PHN. The kinetic analysis revealed that the overall adsorption process was fast and successfully fitted with the pseudo-second-order kinetic model. The anthracene ring makes GO-9-AA $\pi$-electron rich, thus facilitating $\pi-\pi$ EDA interaction between NAP, ACN and PHN with GO-9-AA.
\end{abstract}

Keywords: Wastewater, Aromatic pollutant; Graphene oxide, PAHs

\section{Introduction}

Polycyclic aromatic hydrocarbons (PAHs) are a group of organic compounds that contain two or more fused rings of carbon and hydrogen. They are persistent environmental contaminants and usually arise from incomplete combustion of hydrocarbons and other organic materials such as petroleum, coal, gas, garbage, tobacco, wood, and biomass. ${ }^{1,2}$ PAHs enter the environment from different sources, including combustion fuel gasses, wastewater, and runoff from the petroleum industry. They were identified in industrial and municipal wastewater, effluents, rain, surface and drinking water, soils, and plants. ${ }^{3,4}$ PAHs can transport long distance in air and water due to their chemical persistence and semi-volatile na- ture and are difficult to biodegrade. Presences of PAHs in the environment are of great concern because many of them are toxic, carcinogenic, and they tend to bioaccumulate in aquatic organisms. Some PAHs are capable of interacting with DNA to promote mutagenic and carcinogenic responses. Therefore, they are considered as priority pollutants by both the US Environmental Protection Agency (EPA) and the European Environmental Agency. So, efficient, low-cost and robust methods to decontaminate waters from PAHs are vital to protect human and environment. Numerous studies have focused on the effective elimination of PAHs from aqueous solutions by different strategies such as photocatalysis, adsorption, electrolysis, organobentonite, and sonication. Among these approaches, adsorption removal of PAHs has been considered as 
an efficient technique due to its low-cost, high efficiency and facile operation routes. For the adsorptive removal of PAHs from aqueous environments, various kinds of adsorbents have been extensively investigated. However, the adsorption capacities of aforementioned materials are not sufficient. Therefore, it will be beneficial to develop new adsorbents with higher adsorption capacities for persistent organic pollutant management in the environment.

Carbon-based nanomaterials have unique $\pi$-electronic structure and been used as an excellent sorbents for the removal of aromatic compounds. ${ }^{12-15} \mathrm{GO}$, as a newly found carbon-based nanomaterial with fascinating two-dimensional (2D) atomic structure and only one atomic thickness, have attracted considerable attention in a broad range of application in addressing environmental challenges. ${ }^{16-18}$ Due to its large specific surface area (theoretical limit, $2630 \mathrm{~m}^{2} \mathrm{~g}^{-1}$ ), remarkable electronic properties and high ability of modification, potential environmental applications of GO as a superior adsorbent has been recognized for removal of organic and inorganic contaminants from water and gasses. ${ }^{19,20} \mathrm{GO}$ can be well-dispersed in water due to its abundant hydrophilic groups on its surface such as hydroxyl, carboxylic and epoxide. ${ }^{21,22}$ In addition, the interaction between GO and pollutants is closely related to its surface structure which is tunable and flexible. ${ }^{23,24}$ The surface of GO usually consists of two parts: unoxidized and oxidized zones. The unoxidized zone is referring to the lowly oxidized GOs while oxidized zones consist of both $s p^{3}$ zones and $s p^{2}$ clusters. The oxygen-containing functional groups could be found on the surface of GO in the oxidized zones. The $s p^{2}$ clusters are affinitive to non-electrolytic organic compounds by $\pi-\pi$ stacking or other hydrophobic interactions ${ }^{26,27}$ whereas the oxygen-containing functional groups tend to bind hydrophilic species due to hydrogen bonding, ion exchange or coordination effects. ${ }^{28,29}$ Due to diverse zones of GO with different adsorption affinity, the adsorption behavior of GO mainly depends on its surface structural feature. Therefore, introduction of a suitable functional group on GO surface can improve its adsorption capacity for the removal of target pollutants. In the current research GO was modified and functionalized with 9-aminoanthracene by formation of the chemical bonds between carboxyl groups of GO and amine groups of 9-aminoanthracene to produce GO-9-AA (Scheme 1). The aim of functionalization of GO with 9-aminoanthracene is to increase the $s p^{2}$ clusters in GO for enhancing adsorption of non-electrolytic organic compounds by $\pi-\pi$ stacking or other hydrophobic interactions. The fabricated composite was utilized for the removal of NAP, ACN and PHN as a model of PAHs and adoption mechanism of aforementioned PAHs was also proposed. To the best of our knowledge, this research is the first example of GO-9-AA fabrication and its application for the removal of NAP, ACN and PHN from aqueous solution.

\section{Experimental}

\section{1. Materials}

All reagents were the analytical grade and used without further purification. Graphite powder $(\sim 325$ mesh si-

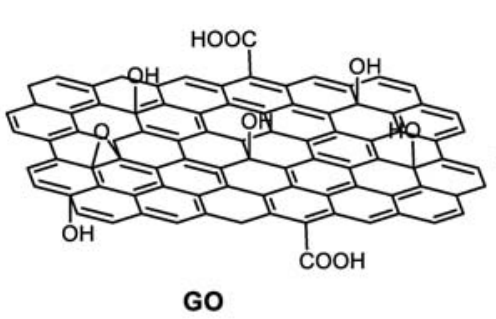

GO

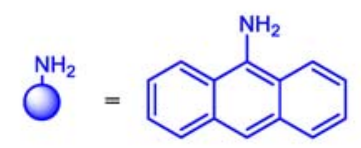

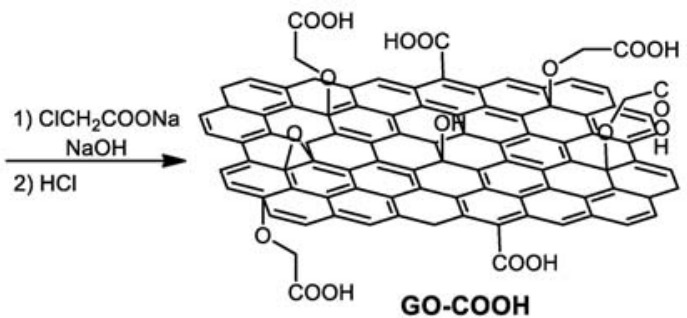
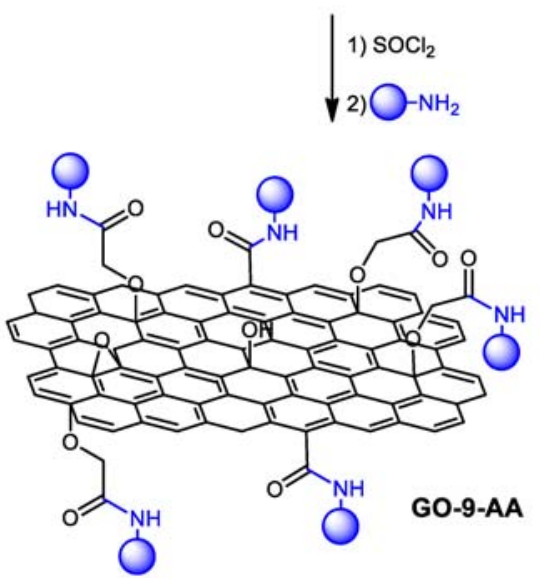

Scheme 1. Schematic illustration of GO-9-AA fabrication 
Table 1. Physicochemical properties of the selected PAHs

\begin{tabular}{|c|c|c|c|c|c|}
\hline PAH's & Structure & $\begin{array}{l}\text { Molecular weight } \\
\left(\mathrm{g} \mathrm{mol}^{-1}\right)\end{array}$ & $\begin{array}{c}\text { Vapour pressure } \\
\text { at } 25^{\circ} \mathrm{C} \mathrm{Pa} \\
\end{array}$ & $\begin{array}{c}\text { Water solubility } \\
\left(\mathrm{g} \mathrm{L}^{-1}\right)\end{array}$ & $\log K_{\text {ow }}$ \\
\hline $\begin{array}{l}\text { Naphthalene } \\
\mathrm{C}_{10} \mathrm{H}_{8}\end{array}$ & & 128 & 10.4 & $31 \sim$ & 3.37 \\
\hline $\begin{array}{l}\text { Acenaphthylene } \\
\mathrm{C}_{12} \mathrm{H}_{8}\end{array}$ & & 152 & 0.9 & 3.93 & 4.00 \\
\hline $\begin{array}{l}\text { Phenanthrene } \\
\mathrm{C}_{14} \mathrm{H}_{10}\end{array}$ & & 178 & 0.02 & 1.2 & 4.57 \\
\hline
\end{tabular}

ze, 99.9995\%) was obtained from Alpha Aesar Company (Karlsruhe, Germany). Sulfuric acid $\left(\mathrm{H}_{2} \mathrm{SO}_{4}\right)$, potassium persulfate $\left(\mathrm{K}_{2} \mathrm{~S}_{2} \mathrm{O}_{8}\right)$, phosphorus pentoxide $\left(\mathrm{P}_{2} \mathrm{O}_{5}\right)$, potassium permanganate $\left(\mathrm{KMnO}_{4}\right)$, hydrogen peroxide $\left(\mathrm{H}_{2} \mathrm{O}_{2}\right)$, hydrochloric acid $\mathrm{HCl}$, hydrazine hydrate $\left(\mathrm{H}_{6} \mathrm{~N}_{2} \mathrm{O}\right)$, nitric acid $\left(\mathrm{HNO}_{3}\right)$, glacial acetic acid, sodium hydroxide (Na$\mathrm{OH})$ and $\mathrm{SnCl}_{2}$ were purchased from Merck Chemical Company (Darmstadt, Germany). NAP, ACN, PHN and anthracene were purchased from Sigma-Aldrich Chemical Company (Dorset, UK). All aqueous solutions were prepared with ultrapure water $(16 \mathrm{M} \Omega . \mathrm{cm})$ from the Milli-Q water purification system (Millipore, Bedford, MA, USA). The physicochemical properties of PAHs are shown in Table 1.

\section{1. 1. Fabrication of GO}

GO was synthesized using modified Hummer's method. Graphite flakes were oxidized using a combination of powerful reagents, i.e., sulfuric acid $\left(\mathrm{H}_{2} \mathrm{SO}_{4}\right)$, potassium persulfate $\left(\mathrm{K}_{2} \mathrm{~S}_{2} \mathrm{O}_{8}\right)$ and phosphorus pentoxide $\left(\mathrm{P}_{2} \mathrm{O}_{5}\right)$. Briefly, $3.0 \mathrm{~g}$ of graphite flakes were suspended in $10 \mathrm{~mL}$ of $\mathrm{H}_{2} \mathrm{SO}_{4}$. Oxidizing agents $\mathrm{K}_{2} \mathrm{~S}_{2} \mathrm{O}_{8}$ and $\mathrm{P}_{2} \mathrm{O}_{5}$ were gradually added to the graphite and sulfuric acid mixture and stirred at $90{ }^{\circ} \mathrm{C}$ until the flakes were dissolved. The stirring continued for 4 more hours at $80^{\circ} \mathrm{C}$, and the solution was then diluted with $500 \mathrm{ml}$ Milli-Q Millipore water. After dilution, the solution was stirred overnight, and then filtered, washed with deionized water and thereafter dried to get the powdered form of GO. Pre-oxidized GO powder was then subjected to further oxidation with $125 \mathrm{~mL}$ of $\mathrm{H}_{2} \mathrm{SO}_{4}$ and $15 \mathrm{~g}$ of potassium permanganate $\left(\mathrm{KMnO}_{4}\right)$ in an ice bath. After 2 more hours stirring, $130 \mathrm{~mL}$ of Milli-Q Millipore water was added to the mixture, and this caused the temperature to rise to $95{ }^{\circ} \mathrm{C}$. After 15 minutes, $15 \mathrm{~mL}$ hydrogen peroxide $(30 \%, \mathrm{v} / \mathrm{v})$ was added to reduce manganese to manganese sulfate $\left(\mathrm{Mn} \rightarrow \mathrm{MnSO}_{4}\right)$. Finally, the solution was diluted with $400 \mathrm{~mL}$ of Milli-Q Millipore water and yellowish suspension was stirred overnight. GO was filtered and washed thoroughly with $\mathrm{HCl}$ and water till the rinsed water $\mathrm{pH}$ was found to be approximately 7 .

\section{1. 2. Preparation of 9-nitroanthracene (3)}

9-nitroanthracene (3, Scheme 2) was prepared according to a previous report. Briefly, concentrated nitric acid $(4 \mathrm{~mL})$ was added dropwise to a suspension of anthracene (1) (10.0 g, $56.0 \mathrm{mmol})$ in glacial acetic acid (40 $\mathrm{mL}$ ) maintaining the temperature below $30^{\circ} \mathrm{C}$. The reaction mixture was stirred vigorously for $1 \mathrm{~h}$ to form a clear solution. Then a mixture of concentrated $\mathrm{HCl}(50$ $\mathrm{mL})$ and glacial acetic acid $(50 \mathrm{~mL})$ was added slowly resulting in a pale yellow precipitate of 9-nitro-10-chloro-9,10-dihydroanthracene (2). The solution was filtered, and washed with glacial acetic acid $(3 \times 25 \mathrm{~mL})$ and thoroughly with water until the washings were neutral. The resulting yellow solid was treated with a warm solution $\left(60-70^{\circ} \mathrm{C}\right)$ of $10 \% \mathrm{NaOH}(200 \mathrm{~mL})$, filtered, washed with warm water until the washings were neutral. Finally, the solid was air-dried and recrystallized from glacial acetic acid affording fluffy yellow needles $(8.31 \mathrm{~g}$, $67 \%$ yield), $\mathrm{mp} 148-150{ }^{\circ} \mathrm{C}$ (lit. $145-146{ }^{\circ} \mathrm{C}$ ). $\mathrm{R}_{\mathrm{f}}=0.30$ ( $n$-hexane/EtOAc 9:1). ${ }^{1} \mathrm{H}$ NMR $\left(300 \mathrm{MHz}, \mathrm{CDCl}_{3}\right) \delta=$ $8.57(1 \mathrm{H}, \mathrm{s}), 8.03(2 \mathrm{H}, \mathrm{d}, J=7.6 \mathrm{~Hz}), 7.92(2 \mathrm{H}, \mathrm{d}, \mathrm{J}=$ $7.6 \mathrm{~Hz}), 7.68-7.52(4 \mathrm{H}, \mathrm{m})$.

\section{1. 3. Preparation of 9 -aminoanthracene (4)}

9-aminoanthracene $(\mathbf{4}$, Scheme 2$)$ was prepared according to the procedure reported by Janovec et al.,. Briefly, a suspension of 9-nitroanthracene (3) (7.24 g, $32.5 \mathrm{mmol})$ in glacial acetic acid $(145 \mathrm{~mL})$ was heated in $70-80^{\circ} \mathrm{C}$ for $1.5 \mathrm{~h}$. To the resulting clear solution was added a slurry of $\mathrm{SnCl}_{2}(31.0 \mathrm{~g}, 163.2 \mathrm{mmol})$ in concentrated $\mathrm{HCl}(110 \mathrm{~mL})$ via a dropping funnel. The resulting yellow precipitate was stirred at $80{ }^{\circ} \mathrm{C}$ for a further 30 min, cooled to room temperature, filtered, washed with concentrated $\mathrm{HCl}(3 \times 10 \mathrm{~mL})$, treated with a solution of $5 \% \mathrm{NaOH}$ for approximately 15 min with manual stirring from time to time. Finally, product was collected by filtration, washed thoroughly with water until the washings were neutral and vacuum-dried at $50{ }^{\circ} \mathrm{C}$ for $6 \mathrm{~h}$ to afford a yellow powder $(5.18 \mathrm{~g}, 83 \%$ yield). No further purification was required, M.p $161-166{ }^{\circ} \mathrm{C}$ (lit. $153-154{ }^{\circ} \mathrm{C}$ ). $\mathrm{R}_{\mathrm{f}}=$ 


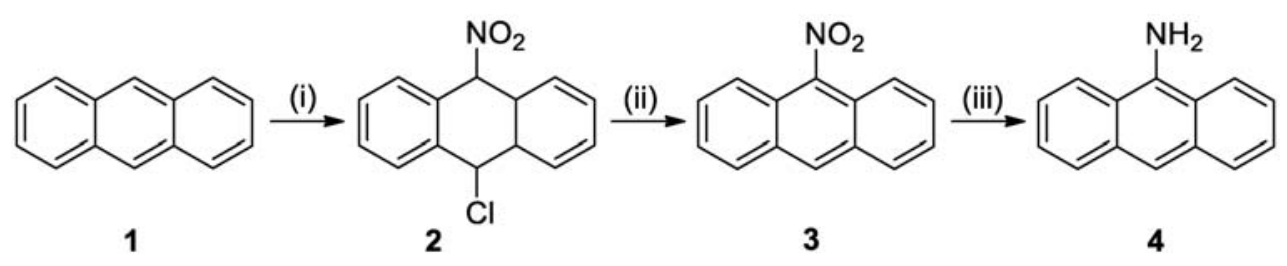

Scheme 2. Schematic illustration of 9 -aminoanthracene synthesis. Reagents and conditions: (i) concd. $\mathrm{HNO}_{3} / \mathrm{HCl},<30{ }^{\circ} \mathrm{C}$; (ii) $\mathrm{NaOH}(10 \%)$, $60-70{ }^{\circ} \mathrm{C}$; (iii) $\mathrm{SnCl}_{2} /$ concd. $\mathrm{HCl}$, glacial $\mathrm{HOAc}, 70-80{ }^{\circ} \mathrm{C}$.

0.39 (n-hexane/EtOAc 3:1). ${ }^{1} \mathrm{H}$ NMR $\left(300 \mathrm{MHz}, \mathrm{CDCl}_{3}\right)$ : $\delta=7.98-7.94(\mathrm{~m}, 4 \mathrm{H}), 7.88(\mathrm{~s}, 1 \mathrm{H}), 7.47-7.39(\mathrm{~m}, 4 \mathrm{H})$, $4.82\left(\mathrm{~s}, 2 \mathrm{H}, \mathrm{NH}_{2}\right)$.

\section{1. 4. Preparation of GO-9-AA}

The GO suspension $(1 \mathrm{mg} / \mathrm{mL})$ was sonicated in the bath under $100 \mathrm{~W}$ power for $1 \mathrm{~h}$. The resulting suspension was taken for further carboxylation and amidation. In carboxylation of $\mathrm{GO}, 1.5 \mathrm{~g} \mathrm{NaOH}$ and $1.5 \mathrm{~g}$ sodium chloroacetate were added into $300 \mathrm{~mL} \mathrm{GO}$ suspension and sonicated in the bath for $1 \mathrm{~h}$ to convert hydroxyl and epoxide groups to carboxyl groups. The resulting mixture was neutralized with diluted $\mathrm{HCl}$, and purified by repeated centrifugation at 4,000 rpm for 45 min and rinsed with ultrapure water, then evaporated to dryness in vacuum yielding a dark black solid product. The carboxylated graphene oxide, $\mathrm{GO}-\mathrm{COOH}$, was reacted in $20 \mathrm{~mL}$ of $\mathrm{SOCl}_{2}$ (containing $2 \mathrm{~mL}$ of dimethylformamide) at $70{ }^{\circ} \mathrm{C}$ for $24 \mathrm{~h}$ to convert the carboxyl groups into acyl chlorides, then evaporated to dryness in the vacuum and resuspended in dry acetonitrile containing 9-aminoanthracene $(500 \mathrm{mg})$. The mixture was stirred vigorously at 50 ${ }^{\circ} \mathrm{C}$ for $48 \mathrm{~h}$ under nitrogen atmosphere, and then the product was purified by repeated centrifugation at 4,000 rpm for 45 min and rinsed with ultrapure water, acetone, and dichloromethane to remove unreacted 9-aminoanthracene. The final product, graphene oxide-9-aminoanthracene (GO-9-AA), was dried at room temperature in vacuum yielding $270 \mathrm{mg}$.

\section{2. Characterization}

The fabricated GO-9-AA was characterized by FTIR, XRD, TGA, TEM and Raman spectroscopy. FTIR spectra of materials were recorded within 400 to $4000 \mathrm{~cm}^{-1}$ region with Shimadzu FTIR 8300 spectrometer in $\mathrm{KBr}$ matrix. Raman spectra were measured using SENTERRA (2009) (BRUKER, Germany). The TGA data were acquired with Shimadzu TA-50 thermal analyzer (Shimadzu, Japan) at heating rate of $5{ }^{\circ} \mathrm{C} \mathrm{min}{ }^{-1}$ from room temperature to $800{ }^{\circ} \mathrm{C}$. High-angle X-ray diffraction patterns were obtained with STOE diffractometer using $\mathrm{Cu}-\mathrm{K} \alpha$ radiation at scanning rate of $3 / \mathrm{min}$ from $2 \theta=5^{\circ}-80^{\circ}$. The morphology of the GO-9-AA was recorded with Philips CM120 transmission electron microscopy (TEM).

\section{3. Batch Adsorption Experimental}

All adsorption experiments were carried out in a batch reactor at $25 \pm 1{ }^{\circ} \mathrm{C}$. Different concentrations of NAP, ACN and PHN (1-30 mg L ${ }^{-1}$ ) were made by preparation of simulated wastewater of three adsorbates (in pure methanol) with DI water. Adsorption experiments were conducted by adding a specific amount of GO-9-AA to the synthetic wastewater, including water/methanol solution $(20 \%$ $\mathrm{v} / \mathrm{v}$ ) in $50 \mathrm{~mL}$ glass centrifuge tubes sealed with Teflon-lined screw caps. During the adsorption experiments, negligible amounts $(0-0.15 \mu \mathrm{L})$ of $0.1 \mathrm{M} \mathrm{HCl}$ or $0.1 \mathrm{M} \mathrm{NaOH}$ were added to the solution for adjusting the $\mathrm{pH}$ to $7.0 \pm 0.1$. After obtaining the equilibrium, the mixture was centrifuged at $6000 \mathrm{rpm}$ for $10 \mathrm{~min}$, and then concentrations of the solutes in the supernatants phase were measured by UV/visible spectrophotometer (UV/Vis 2100 Shimadzu).

\section{4. Data Analysis}

The equilibrium data of the adsorption experiments were fitted with two conventional isotherm models, i.e. Langmuir and Freundlich to determine the theoretical maximum adsorption capacity of the GO-9-AA. Based on the Langmuir isotherm model, adsorption process takes place on a homogeneous surface by monolayer adsorption, and there is no interaction between adsorbed particles. It is formulated as:

$$
q_{e}=\frac{q_{m} b c_{e}}{1+b c_{e}}
$$

Where $\mathrm{C}_{\mathrm{e}}$ is the equilibrium concentration of the adsorbate in $\mathrm{mg} \mathrm{L}^{-1}, \mathrm{q}_{\mathrm{e}}$ the amount of PAHs adsorbed at equilibrium in $\mathrm{mg} \mathrm{g}^{-1}, \mathrm{q}_{\mathrm{m}}$ and $\mathrm{b}$ are the Langmuir constants which demonstrate the adsorption capacity of adsorbent and apparent heat change in $\mathrm{mg} \mathrm{g}^{-1}$ and $1 \mathrm{mg}^{-1}$, respectively.

Dimensionless constant separation factor $\left(\mathrm{R}_{\mathrm{L}}\right)$ reflects the fundamental characteristics of Langmuir model, and it is expressed as:

$$
R_{L}=\frac{1}{1+b C_{0}}
$$

Where $\mathrm{b}$ is the Langmuir constant and $\mathrm{C}_{0}$ is the highest initial concentration of adsorbate $\mathrm{mg} \mathrm{L}^{-1}$. The 
value of $R_{L}$ illustrates the types of Langmuir isotherm. Adsorption phenomenon is irreversible $\left(\mathrm{R}_{\mathrm{L}}=0\right)$, favorable $\left(0<\mathrm{R}_{\mathrm{L}}<1\right)$, linear $\left(\mathrm{R}_{\mathrm{L}}=1\right)$, or unfavorable $\left(\mathrm{R}_{\mathrm{L}}\right.$ $>1)$. The Freundlich isotherm model assumes that adsorption process is multilayer and occurs on heterogeneous surfaces. The Freundlich isotherm model is given by:

$$
q_{e}=K_{F} C_{e}^{1 / n}
$$

Where $K_{F}\left(\mathrm{mg}^{(\mathrm{n}-1) / \mathrm{n}} \mathrm{g}^{-1} \mathrm{~L}^{-1}\right)$ and $\mathrm{n}$ are Freundlich isotherm model constants, representative of the saturation capacity and intensity of adsorption process.

The Kinetics of the adsorption of the NAP, ACN, and PHN onto GO-9-AA were investigated by fitting the adsorption data with pseudo first-order and pseudo-second-order kinetic models. The pseudo-first order assumes that adsorption rate is a proportion with the number of free adsorption sites and it is formulated as:

$$
\log \left(q_{e}-q_{t}\right)=\log q_{e}-\frac{k_{1}}{2.303} t
$$

Where $\mathrm{q}_{\mathrm{e}}$ and $\mathrm{q}_{\mathrm{t}}$ are the amounts of NAP, ACN and PHN adsorbed ( $\mathrm{mg} \mathrm{g}^{-1}$ ) onto GO-9-AA at equilibrium and any time $\mathrm{t}(\mathrm{min})$, respectively, and $\mathrm{k}_{1}$ is the rate constant of the adsorption process $\left(\mathrm{min}^{-1}\right)$.

The linear relationship between adsorption rate and the square of the number of unoccupied adsorption sites is an assumption of the pseudo-second order kinetic model, and it is given by:

$$
\frac{t}{q_{t}}=\frac{1}{k_{2} q_{e}^{2}}+\frac{t}{q_{e}}
$$
$\left.\min ^{-1}\right)$.

Where $\mathrm{k}_{2}$ is the adsorption rate constant $\left(\mathrm{mg} \mathrm{g}^{-1}\right.$

All of the isotherm and kinetic model parameters were obtained by fitting the models in Sigma Plot 12.0 .

\section{Results and Discussion}

\section{1. Preparation of GO-9-AA}

After modification of the GO surface by a chlorine group using thionyl chloride, the reaction of highly reactive chlorine with the amino group of 9-aminoanthracene is led to the formation of title sorbent. Pyridine was added to the reaction mixture to react with the side product $(\mathrm{HCl})$. The formation of GO-9-AA nanocomposite was confirmed by IR spectroscopy, elemental analysis, thermal gravimetric analysis, Raman spectroscopy, powder X-ray diffraction and transmission electron microscopy.

\section{2. Characterization of GO-9-AA}

\section{2. 1. FTIR Analysis}

The FTIR spectra of GO and GO-9-AA are shown in Figure 1. The appearance of characteristic absorption peaks at $3449,1735,1631$ and $1067 \mathrm{~cm}^{-1}$ revealed the stretching vibrations of $-\mathrm{OH}, \mathrm{C}=\mathrm{O}, \mathrm{C}=\mathrm{C}$, and $\mathrm{C}-\mathrm{O}$ functional groups in $\mathrm{GO}$, respectively. After the amidation reaction, several new peaks appeared on the FTIR spectrum of GO-9-AA. The amide characteristic $(-\mathrm{C}(\mathrm{O}) \mathrm{NH}-)$ stretching vibration peak at $1653 \mathrm{~cm}^{-1}$ indicates that the amide bond formed by reaction between GO and 9-aminoanthrace. Furthermore, the new peak at $1573 \mathrm{~cm}^{-1}$ corresponds to the $\mathrm{N}-\mathrm{H}$ bending vibration and the peak at $1192 \mathrm{~cm}^{-1}$ for $\mathrm{C}-\mathrm{N}$ in-plane stretching demonstrates that the 9-aminoanthracene was grafted onto the GO by the amide bond.

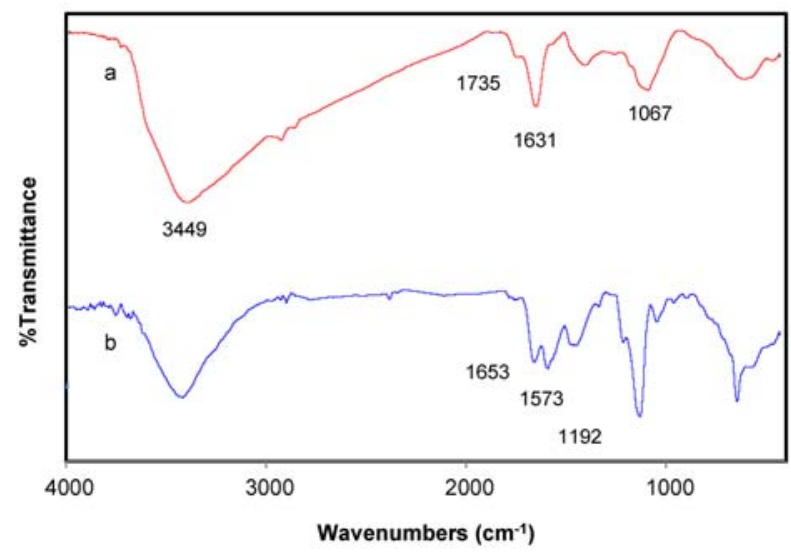

Fig. 1. FT-IR spectra of (a) GO and (b) GO-9-AA

\section{2. 2. Raman Spectroscopy}

Raman spectroscopy as a powerful tool has been frequently used to investigate the structural and electronic

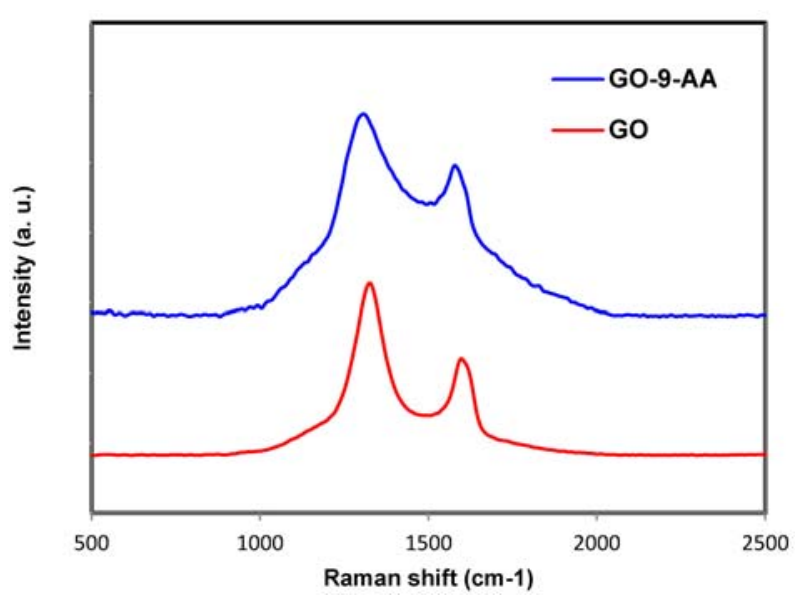

Fig. 2. Raman spectra of GO and GO-9-AA 
properties of GO. Figure 2 shows the Raman spectra of the pristine GO and GO-9-AA. As expected, the pristine GO displays a prominent G-band (graphitic band) at 1598 $\mathrm{cm}^{-1}$ which is due to the influence of defects and isolated double bonds, and D-band (disorder band) at $1326 \mathrm{~cm}^{-1}$. The D-band in carbon materials is associated with the presence of ždisorder' such as defects or simply nanoscale dimensions. The significant structural changes occurring during the amidation reaction were also reflected in the Raman spectra. In GO-9-AA, the G band shifts back to $1579 \mathrm{~cm}^{-1}$ which is relatively close to the G-band of the pristine graphite compared with GO, suggesting that electronic conjugation in GO-9-AA was restored after 9-aminoanthracene grafting on GO structure. ${ }^{38,39}$

\section{2. 3. TGA Analysis}

Strong evidence for successful functionalization of the GO with 9-aminoantheracene was also provided via TGA analysis (Fig. 3). GO shows slight mass lose from room temperature to $210{ }^{\circ} \mathrm{C}$ and significant mass lose from 210 to $230^{\circ} \mathrm{C}$. Following with slight mass lose up to $600{ }^{\circ} \mathrm{C}$. The major mass lose at $\sim 220{ }^{\circ} \mathrm{C}$ is caused by pyrolysis of the oxygen-containing functional groups, generating $\mathrm{CO}, \mathrm{CO}_{2}$, and stream. In compared with $\mathrm{GO}$, TGA of GO-9-AA shows an enhanced thermal stability due to the removal of oxygen-containing functional groups by amidation reaction. This change led to a new thermal decomposition at $490-570{ }^{\circ} \mathrm{C}$ which attributed to the formation of amide-bounds of 9-aminoanthracene functional group. This mass changes indicate successful covalent functionalization of GO by 9-aminoanthracene which was also in agreement with the results of FTIR and Raman analysis.

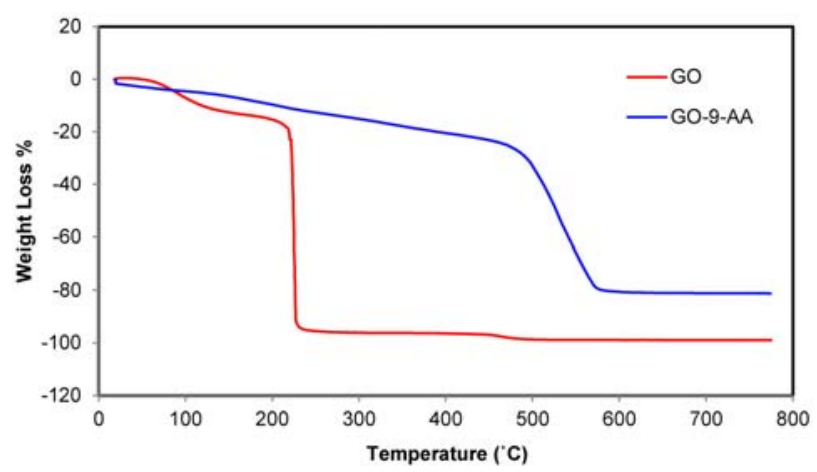

Fig. 3. TGA of GO and GO-9-AA

\section{2. 4. XRD Analysis}

Figure 4 shows XRD patterns of both pristine GO and GO-9-AA. The peak at $11.06^{\circ}$ corresponds to the (001) diffraction with an interlayer spacing of approximately $0.74 \mathrm{~nm}$. As it can be seen, this peak in XRD pattern

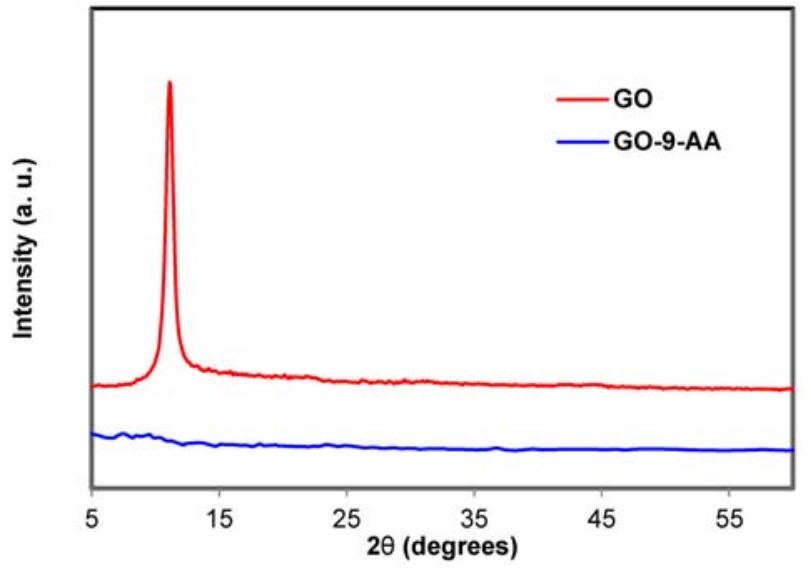

Fig. 4. X-ray diffraction patterns of GO and GO-9-AA

of GO after amidation has been eliminated, suggesting exfoliation of layered in GO-9-AA.

\section{2. 5. TEM Analysis}

The natural structure of GO could be proved by natural ripples on the GO surfaces. The microstructure of the sorbent before and after modification was investigated by TEM analysis. The TEM images demonstrated that both GO and GO-9-AA nanosheets were transparent (Figure 5). As it can be seen, GO has fairly flat surface compared with that of GO-9-AA and its wrinkles were mainly positioned on the boundary regions of the GO and created scrolls, whereas the surface of GO-9-AA has more aggregations and wrinkles which mostly on the basal planes to make groove regions.

\section{3. Adsorption Isotherms}

Describing the interaction between adsorbent and the adsorbate is usually the aim of adsorption isotherm models when the adsorption process reaches equilibrium. The isotherm models allow having the most vital parameter for designing an appropriate adsorption system. The adsorption isotherms of NAP, ACN, and PHN on GO-9AA are shown in Figure 6, and the regression parameters are listed in Table 2. In general, all adsorption isotherms were nonlinear, and the regression parameters are listed in Table 2. The results indicated that the nonlinear correlation coefficients of the Freundlich isotherm model for NAP, ACN, and PHN onto GO were 0.991, 0.997 and 0.997, and onto GO-9-AA were 0.998, 0.997 and 0.997, respectively. The higher correlation coefficients for Freundlich model imply that adsorption process takes place mostly onto heterogeneous regions such as edges, grooves, and wrinkles. The same result has also been reported in the removal of PAHs by other adsorbent materials such as modified periodic mesoporous organosilica, GO and graphene. ${ }^{45,46}$ Based on Langmuir isotherm mo- 

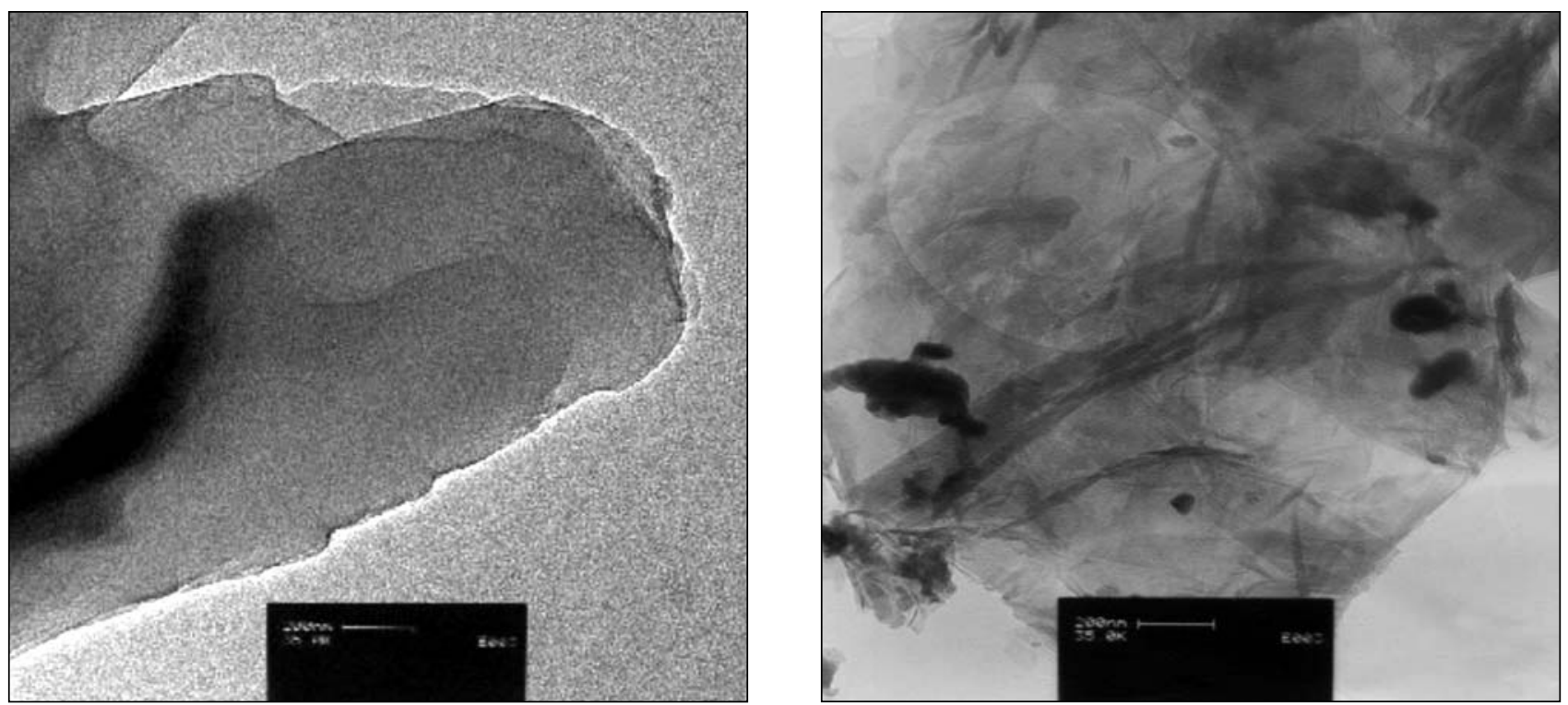

Fig. 5. TEM micrograph of GO (left) and GO-9-AA (right)

Table 2. Isotherm parameters for NAP, ACN, and PHN adsorption onto GO and GO-9-AA

\begin{tabular}{|c|c|c|c|c|c|c|c|c|c|}
\hline & \multicolumn{5}{|c|}{ Langmuir } & & \multicolumn{3}{|c|}{$\begin{array}{l}\text { Freundlich } \\
\end{array}$} \\
\hline & Adsorbates & $\underset{\left(\mathbf{m g ~ g}^{-1}\right)}{\mathbf{q}_{\mathrm{m}, \mathrm{cal}}}$ & $\underset{\left(\mathbf{m g ~ g}^{-1}\right)}{\mathbf{q}_{\mathbf{e}, \mathbf{e x p}}}$ & b $\left(\mathbf{l ~ m g}^{-1}\right)$ & $\mathbf{R}_{\mathbf{L}}$ & $\mathbf{R}^{2}$ & $\begin{array}{c}\mathbf{K f}\left(\mathbf{m} \mathbf{g}^{(\mathbf{n}-\mathbf{1}) / \mathbf{n}}\right. \\
\left.\mathbf{g}^{-1} \mathbf{L}^{-1}\right)\end{array}$ & $\mathbf{N}$ & $\mathbf{R}^{2}$ \\
\hline \multirow{3}{*}{ GO } & NAP & 22.93 & 23.16 & 0.52 & 0.18 & 0.987 & 9.43 & 3.40 & 0.991 \\
\hline & $\mathrm{ACN}$ & 18.80 & 21.28 & 0.38 & 0.21 & 0.995 & 4.93 & 2.22 & 0.997 \\
\hline & PHN & 17.83 & 19.30 & 0.34 & 0.23 & 0.988 & 4.71 & 2.19 & 0.997 \\
\hline \multirow{3}{*}{ GO-9-AA } & NAP & 57.00 & 78.08 & 1.31 & 0.09 & 0.994 & 42.18 & 2.06 & 0.998 \\
\hline & $\mathrm{ACN}$ & 46.32 & 57.60 & 0.59 & 0.16 & 0.995 & 21.18 & 2.26 & 0.997 \\
\hline & PHN & 44.50 & 52.02 & 0.58 & 0.17 & 0.994 & 18.95 & 2.32 & 0.997 \\
\hline
\end{tabular}
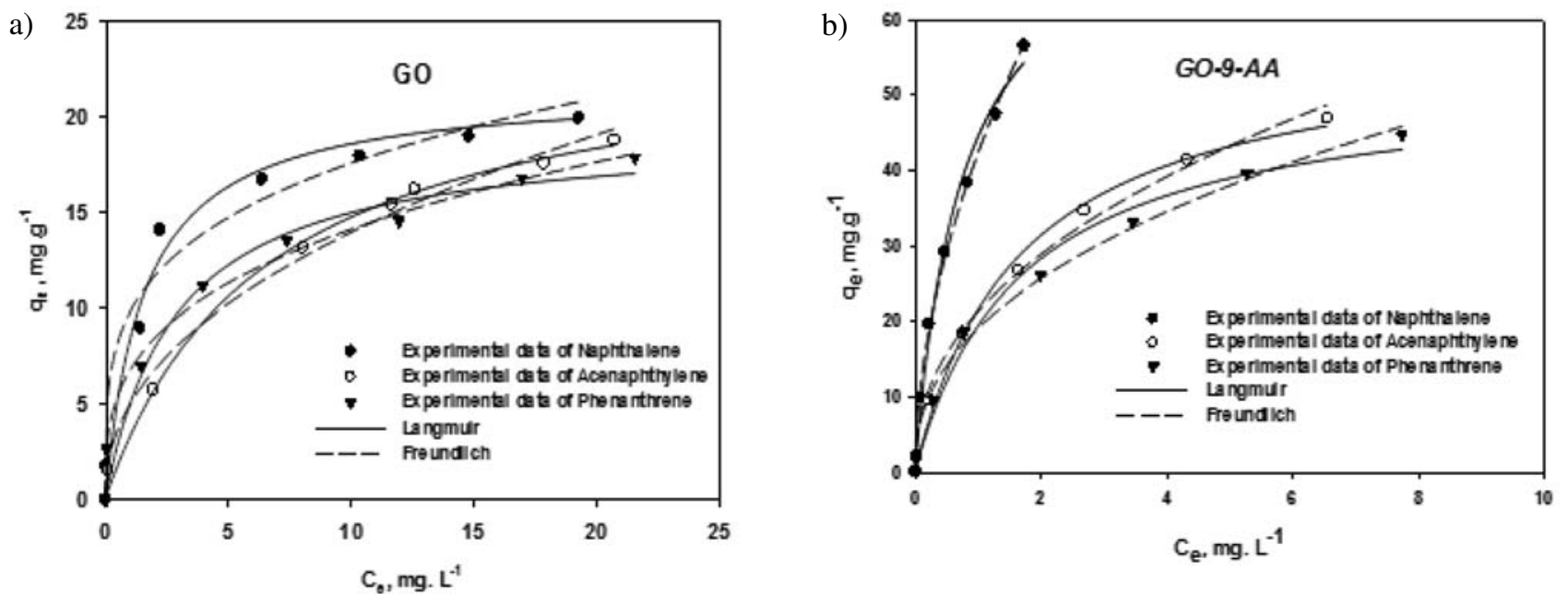

Fig. 6. Adsorption isotherms of NAP, ACN, and PHN onto GO and GO-9-AA at room temperature and $\mathrm{pH}=7.0$

del, maximum theoretical adsorption capacity $\left(q_{m, c a l}\right)$ were obtained $23.16,21.28$ and $19.30 \mathrm{mg} \mathrm{g}^{-1}$ onto GO and 78.08, 57.60 and $52.02 \mathrm{mg} \mathrm{g}^{-1}$ onto GO-9-AA for NAP,
$\mathrm{ACN}$, and PHN, respectively. The same trends were observed for experimental adsorption capacities $\left(q_{e, \text { exp }}\right)$ i.e., 22.93, 18.80 and $17.83 \mathrm{mg} \mathrm{g}^{-1}$ for NAP, ACN and PHN 
onto GO and 57.00, 46.33 and $44.50 \mathrm{mg} \mathrm{g}^{-1}$ onto GO-9AA, respectively. Separation factor $\left(\mathrm{R}_{\mathrm{L}}\right)$, derived from the Langmuir isotherm model was also calculated (Table 2) to prove the favorableness of the adsorption of three adsorbates onto GO and GO-9-AA. The values of $\mathrm{R}_{\mathrm{L}}$ are calculated in the range of $0.09-0.23$ demonstrating a favorable adsorption process of NAP, ACN, and PHN. Adsorption intensity of adsorbates could be attributed to the Freundlich constant $(1 / \mathrm{n})$. Adsorbates could be easily adsorbed when $0.1<1 / \mathrm{n} \leq 0.5$, adsorption process of the adsorbates is difficult when $0.5<1 / \mathrm{n} \leq 1$, and when $1 / \mathrm{n}>1$ adsorption is entirely difficult to occur. The $1 / \mathrm{n}$ values of NAP, ACN, and PHN onto two adsorbents were calculated in the range of 0.1-0.5 proofing that the adsorbates could be easily adsorbed. Since GO-9-AA showed a notable adsorption capacity in comparison with GO, it was selected to precede extra adsorption experiments.

\section{4. Adsorption Kinetics}

Rapid treatment of a large volume of drinking water is the main factor which sometimes limits practical application of the adsorbents. In order to investigate the required time for obtaining adsorption equilibrium, kinetic studies were performed. The effect of adsorption time on the removal of NAP, ACN, and PHN by GO-9-AA is shown in Figure 7. Adsorption kinetic data were evaluated with two

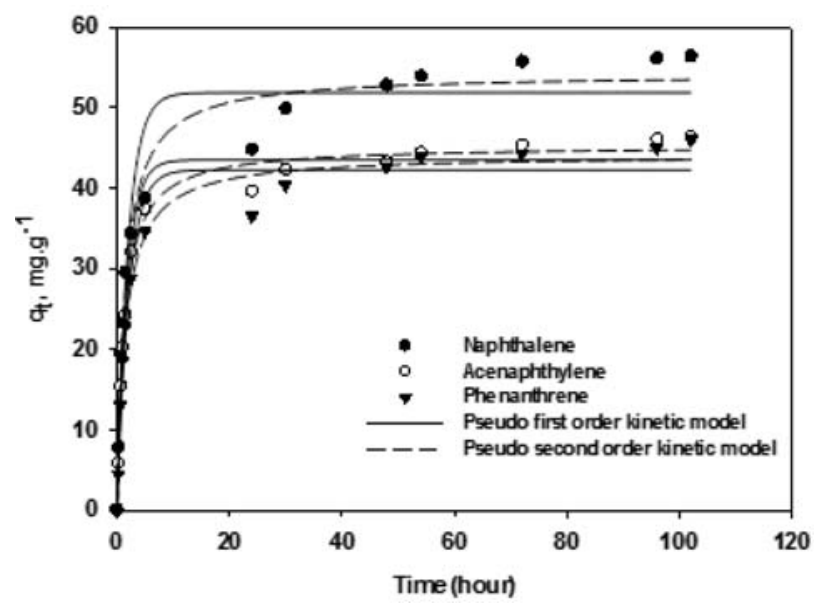

Fig. 7. Adsorption kinetics of NAP, ACN, and PHN on GO-9-AA at room temperature and $\mathrm{pH}=7.0$. semi-empirical kinetic models: the pseudo-first and second-order equations. The validity of two models was investigated by nonlinear regression. It can be seen from Figure 7 , the adsorption rate was quite fast with the order of magnitude NAP > PHN > ACN within the first $20 \mathrm{~h}$, and then gradually slowed down until equilibrium was reached within $48 \mathrm{~h}$ which quite similar to that reported for aromatic compounds. Parameters obtained with two models are summarized in Table 3. As depicted in Figure 7 and Table 3 , predicted adsorption data of NAP, ACN, and PHN onto GO-9-AA by pseudo-second order kinetic model showed a quite good agreement with measured data for both fast and the slow adsorption steps (nonlinear correlation coefficients of the model for NAP, ACN, and PHN onto GO-9AA were 0.991, 0.996 and 0.994, respectively). Constant rates of NAP, ANC, and PHN adsorption, in the liquid phase, are comparable to those calculated for other aromatic hydrocarbons on different adsorbents. The experimental values of $\mathrm{q}_{\mathrm{e}}$ for NAP, ACN, and PHN were 56.3, 46.24 and $45.92 \mathrm{mg} \mathrm{g}^{-1}$, respectively, which are consistent with the $\mathrm{q}_{\mathrm{e}}$ values calculated from the pseudo-second order model which summarized in Table 3. The good agreement of adsorption kinetic data with pseudo-second order model indicates that adsorption of the target adsorbates on GO-9-AA is due to a chemical adsorption.

\section{5. Comparison of Adsorption Behavior Based on Literature Data}

The efficacy of GO-9-AA adsorbent was evaluated in comparison with other adsorbents (Table 4). As it can be seen, the sorption capacity of PAHs on GO-9-AA composites is much higher than other adsorbents.

\section{6. Desorption}

For the environmental protection and economic purposes, adsorbents should both have adequate capacity to decrease the pollutants concentration to satisfy environmental protection agencies standards and have been recycled and reused in successive cycles because they might have either precious raw substance or consist of hazardous materials. The recycling NAP, ACN, PHN and the regeneration of GO-9-AA are illustrated in Figure 8. The adsorption-desorption experiment results demonstrated that the efficiency of the applied GO-9-AA adsorbent

Table 3. Kinetic parameters of NAP, ACN, and PHN adsorption on GO-9-AA

\begin{tabular}{|c|c|c|c|c|c|c|c|}
\hline \multirow[b]{2}{*}{ Adsorbates } & & \multicolumn{3}{|c|}{ Pseudo-first-order } & \multicolumn{3}{|c|}{ Pseudo-second-order } \\
\hline & & $\underset{\left(\mathbf{m i n}^{-1}\right)}{\mathbf{k}_{1}}$ & $\underset{\left(\mathbf{m g ~ g}^{-1}\right)}{\mathbf{q}_{\mathrm{e}} \mathbf{e x p}}$ & $\mathbf{R}^{2}$ & $\mathbf{q}_{\mathrm{e}, \mathrm{cal}}$ & $\begin{array}{c}\mathbf{k}_{2}\left(\mathbf{m g ~ g}^{-1}\right. \\
\left.\min ^{-1}\right)\end{array}$ & $\begin{array}{c}\mathbf{q}_{\mathrm{e}, \mathrm{cal}} \mathbf{R}^{2} \\
\left(\mathbf{m g ~ g}^{-1}\right)\end{array}$ \\
\hline NAP & 56.30 & 0.50 & 51.79 & 0.974 & 0.71 & 54.14 & 0.991 \\
\hline $\mathrm{ACN}$ & 46.24 & 0.56 & 43.41 & 0.991 & 0.80 & 45.21 & 0.996 \\
\hline PHN & 45.92 & 0.49 & 42.16 & 0.985 & 0.67 & 44.09 & 0.994 \\
\hline
\end{tabular}

Balati et al.: Functionalization of Graphene Oxide ... 
Table 4. Comparison of maximum adsorption capacity of different adsorbents for adsorption of PAHs

\begin{tabular}{|c|c|c|c|c|c|}
\hline Adsorbent & Adsorbate & $\begin{array}{c}\text { Adsorption capacity } \\
\left(\mathrm{mg.g}^{-1}\right)\end{array}$ & $\begin{array}{c}\text { Temperature } \\
\left({ }^{\circ} \mathbf{C}\right)\end{array}$ & $\begin{array}{l}\text { Equilibrium } \\
\text { Time (hour) }\end{array}$ & References \\
\hline & NAP & 1.63 & & & \\
\hline \multirow{2}{*}{ SBA-15- $\mathrm{NH}_{2}$} & $\mathrm{ACN}$ & 1.01 & 25 & 10 & 44 \\
\hline & PHN & 0.60 & & & \\
\hline PMO & NAP & 46.64 & 28 & 50 & 45 \\
\hline RHAC & NAP & 63.60 & 28 & 120 & 46 \\
\hline Activated carbon (Coconut Shell) & PHN & 20.22 & 25 & 1 & 47 \\
\hline Multilayer Graphene & PHN & 28.1 & 25 & NA & 48 \\
\hline MWCNT30 & PHN & 14.1 & 25 & NA & 49 \\
\hline Biochar & PHN & 14 & 25 & 672 & 50 \\
\hline C60, Fullerene & NAP & 2.3 & 25 & 72 & 51 \\
\hline Activated carbon & NAP & 58.36 & 25 & 280 & 52 \\
\hline \multirow[t]{2}{*}{ Zeolite } & NAP & 29.59 & 25 & 6 & 53 \\
\hline & NAP & 78.08 & & & \\
\hline \multirow[t]{2}{*}{ GO-9-AA } & $\mathrm{ACN}$ & 57.60 & 25 & 72 & Present study \\
\hline & PHN & 52.02 & & & \\
\hline
\end{tabular}

was satisfactory for the removal of target PAHs by removing 94\% (56.50 $\mathrm{mg} \mathrm{g}^{-1}$ ), 79\% (46.92 $\mathrm{mg} \mathrm{g}^{-1}$ ), and 74\% (44.24 $\mathrm{mg} \mathrm{g}^{-1}$ ) of NAP, ACN, and PHN, respectively in the first cycle. As can be noticed on Figure 8, the absorption capacity of GO-9-AA remained essentially the same after five successive cycles of testing. After fifth adsorption-desorption experiments, the efficiency of GO-9AA was $83.5 \%$ (50.09 $\left.\mathrm{mg} \mathrm{g}^{-1}\right), 68 \%\left(41.00 \mathrm{mg} \mathrm{g}^{-1}\right)$, and $66 \%$ (39.90 $\mathrm{mg} \mathrm{g}^{-1}$ ) of NAP, ACN, and PHN, respectively. The negligible decrease in the GO-9-AA capacity (around 10\%) revealed the good reusability and stability of this adsorbent; therefore, it could be a suitable choice to be used efficiently for the treatment of wastewater polluted by PAHs.

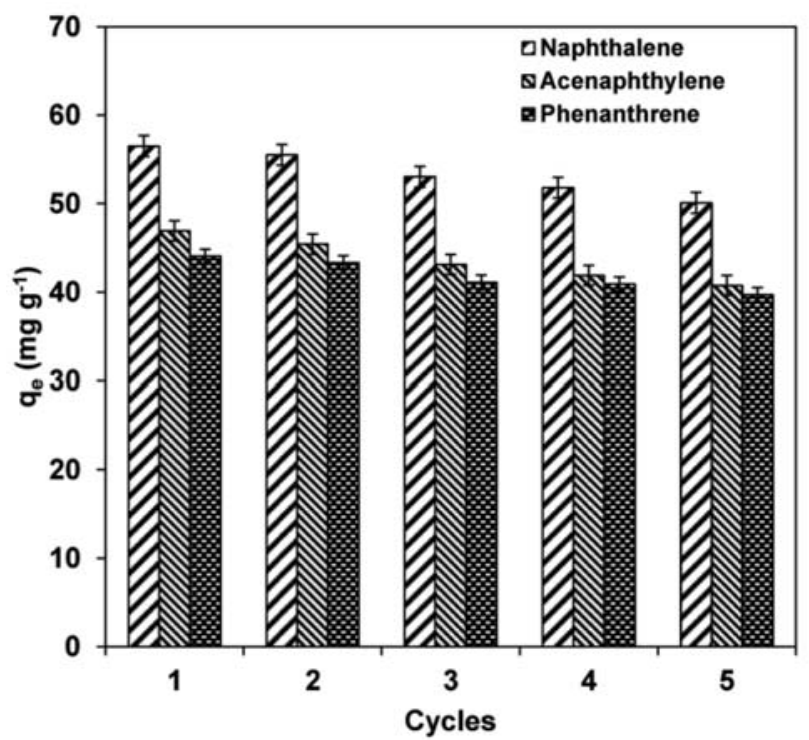

Fig. 8. Recycling of GO-9-AA in the adsorption of NAP, ACN, and $\mathrm{PHN}$, at room temperature. and $\mathrm{pH}=7.0$

\section{7. Adsorption Mechanism}

Isotherm and kinetic parameters of NAP, ACN, and PHN adsorption on GO-9-AA are listed in Table 2 and 3, respectively. As it can be seen, the maximum adsorption capacity $\left(\mathrm{q}_{\mathrm{e}}\right)$ for three adsorbates are in the following order of magnitude NAP $>$ ACN $>$ PHN onto GO-9-AA. A similar behavior was also observed for the adsorption coefficient $\left(K_{\mathrm{d}}=q_{\mathrm{e}} / C_{\mathrm{e}}\right.$, in Fig.9) values at different equilibrium concentrations. As it depicted in Figure 9, adsorption coefficients for NAP, ACN, and PHN have a similar trend. However, a marked decrease in the $K_{\mathrm{d}}$ values for the three adsorbates (magnitude of decrease was in the order of NAP $>\mathrm{ACN}>\mathrm{PHN}$ ) was different. Based on the assumptions of Freundlich isotherm model, removal of NAP, $\mathrm{ACN}$, and PHN by heterogeneous adsorption onto GO-9AA is concerning to the presence of high surface energy sites, such as defects, edges, and groove areas. ${ }^{60,61}$ In this case, three adsorbates would primarily be adsorbed with high affinities to these regions. Inherent surface heterogeneity on GO and increasing the amount of groove and folded regions of GO after functionalization (Figure 5) give rise to charge in homogeneities into the modified GO. Uneven charge sharing on the GO-9-AA could generate high active region in wrinkles and defect parts from the chemical perspective; as a result, NAP, ACN, and PHN could be adsorbed more in these active sites. As Figure 9 shows, adsorption coefficient values for three adsorbates reduce considerably with increasing concentrations, which is in agreement with the $\mathrm{K}_{\mathrm{d}}-\mathrm{C}_{\mathrm{e}}$ curve obtained in the current study for GO-9-AA.

Figure 9 shows that the adsorption of three adsorbates is favorable at a low concentration. Also, the starting point and decreasing slope for NAP is larger than the other two adsorbates, i.e., ACN, and PHN which shows adsorption of NAP is more favorable than ACN, and PHN. Nevertheless, this is not consistent with the hydrophobi- 


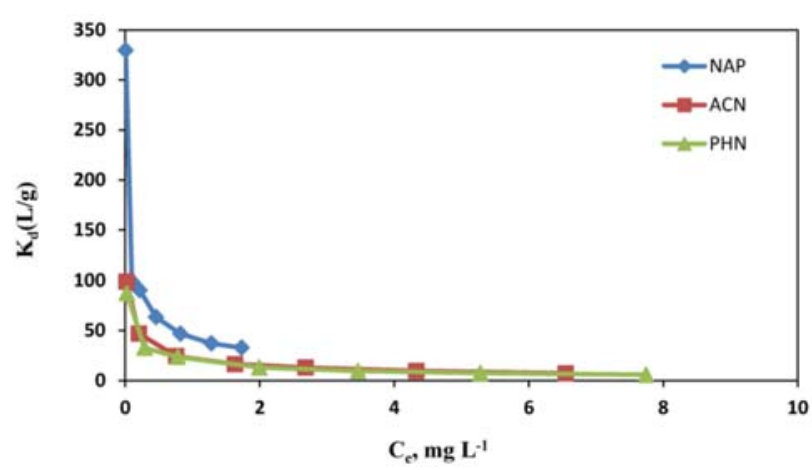

Fig. 9. Adsorption coefficients of NAP, ACN, and PHN onto GO-9AA in different concentrations

city $\left(\mathrm{K}_{\mathrm{ow}}\right)$ trend of the target PAHs, i.e., $\mathrm{PHN}>\mathrm{ACN}>\mathrm{NAP}$. Wang and et al. suggested that different adsorption capacities of PAHs by carbonic adsorbents after eliminating hydrophobic effect might be due to sieving effect. Since adsorption of NAP, especially in the low concentration with approximately high solubility range is more favorable than ACN, and PHN; this shows more heterogeneous regions such as wrinkle surfaces, which have rich $\pi$-electron density onto GO-9-AA and readily available for the molecule with a smaller size.

Finally, several possible interactions between GO-9AA and aromatic compounds (as an adsorbate) are responsible for the adsorption of NAP, ACN, and PHN. These interactions are a hydrophobic effect, electrostatic and electron donor-acceptor (EDA). Based on the adsorption mechanism between aromatic compounds and carbonaceous adsorbents ${ }^{63}$ EDA interaction was proposed to be the main mechanism for adsorption of NAP, ACN, and PHN on GO-9-AA. One type of EDA interaction is $\pi-\pi$ EDA interaction. $\pi-\pi$ EDA interaction is specific and noncovalent, that exists between electron-rich and electron-poor compounds. The existence of anthracene rings on GO-9AA makes it more electron-rich; therefore, the $\pi-\pi$ EDA interactions between three adsorbates and GO-9-AA surface will be stronger and easier.

\section{Conclusion}

GO-9-AA composite was successfully prepared via a facial strategy, characterized and its performance evaluated for the removal of NAP, ACN, and PHN. Incorporation of 9-aminoanthracene in the structure of GO led to both high adsorption capacity and fast removal kinetics that was proved by isotherm and kinetic experiments. The adsorption isotherm and kinetic data were fitted better by Freundlich and pseudo-second-order, respectively. It seems that more conformational change of GO after functionalization with 9-aminoanthracene and stronger electron donor-acceptor interaction between NAP, ACN, and PHN with modified GO are the main reasons for higher adsorption capacity of GO-9-AA for the removal of the target adsorbates. Furthermore, the adsorption efficacy of GO-9-AA was evaluated in comparison with other adsorbents. The results showed that the adsorption capacity of GO-9-AA for the removal of target PAHs is much higher than other adsorbents. Therefore, GO-9-AA could be considered as a promising adsorbent for the removal of PAHs from water in real world applications.

\section{Acknowledgements}

The financial support from the Iranian National Science Foundation (Grant No. 93026590) and University of Kashan is gratefully acknowledged.

\section{References}

1. H. Guo, T. Jiao, Q. Zhang, W. Guo, Q. Peng and X. Yan, Nanoscale Res. Lett. 2015, 10, 272. https://doi.org/10.1186/s11671-015-0931-2

2. A. Balati, A. Shahbazi, M. M. Amini, S. H. Hashemi and K. Jadidi, Eur. J. Environ. Sci. 2014, 4.

3. D. P. Arfsten, D. J. Schaeffer and D. C. Mulveny, cotoxicol. Environ. Saf. 1996, 33, 1-24.

https://doi.org/10.1006/eesa.1996.0001

4. M. Maier, D. Maier and B. Lloyd, Water Res 2000, 34, 773786. https://doi.org/10.1016/S0043-1354(99)00230-4

5. X. Zhang, S. Xie, M. C. Paau, B. Zheng, H. Yuan, D. Xiao and M. M. F. Choi, J. Chromatogr. A 2012, 1247, 1-9. https://doi.org/10.1016/j.chroma.2012.05.047

6. S.-S. Cai, J. A. Syage, K. A. Hanold and M. P. Balogh, Anal. Chem 2009, 81, 2123-2128. https://doi.org/10.1021/ac802275e

7. Y. Ide, Y. Nakasato and M. Ogawa, J. Am. Chem. Soc 2010 , 132, 3601-3604. https://doi.org/10.1021/ja910591v

8. W. Chen, L. Duan, L. Wang and D. Zhu, Environ. Sci. Technol 2008, 42, 6862-6868. https://doi.org/10.1021/es8013612

9. G. D. Sheng, D. D. Shao, X. M. Ren, X. Q. Wang, J. X. Li, Y. X. Chen and X. K. Wang, J Hazard Mater 2010, 178, 505516; https://doi.org/10.1016/j.jhazmat.2010.01.110

10. Y. Huang, A. N. Fulton and A. A. Keller, Sci. Total Environ 2016, 571, 1029-1036. https://doi.org/10.1016/j.scitotenv.2016.07.093

11. P. Zuman and J. Ludvík, Electroanalysis 2000, 12, 879-888. https://doi.org/10.1002/1521-4109(200008)12:12<879: :AID-ELAN879>3.0.CO;2-O

12. Z. Wu and L. Zhu, J Environ Sci 2012, 24, 248-253. https://doi.org/10.1016/S1001-0742(11)60780-8

13. D. T. Sponza and R. Oztekin, Chem. Eng. j. 2010, 162, 142150. https://doi.org/10.1016/j.cej.2010.05.014

14. D. T. Sponza and R. Oztekin, Bioresour Technol 2010, 101, 8639-8648.

https://doi.org/10.1016/j.biortech.2010.06.124 
15. S. Rengaraj, Y. Kim, C. K. Joo and J. Yi, J. Colloid Interface Sci 2004, 273, 14-21. https://doi.org/10.1016/j.jcis.2004.01.007

16. X. Luo, K. Ma, T. Jiao, R. Xing, L. Zhang, J. Zhou and B. Li, Nanoscale Res. Lett 2017, 12, 99. https://doi.org/10.1186/s11671-017-1864-8

17. R. Xing, T. Jiao, Y. Liu, K. Ma, Q. Zou, G. Ma and X. Yan, Polym. Sci. 2016, 8, 181.

18. X. Zhao, K. Ma, T. Jiao, R. Xing, X. Ma, J. Hu, H. Huang, L. Zhang and X. Yan, Sci. Rep 2017, 7.

19. G. K. Ramesha, A. Vijaya Kumara, H. B. Muralidhara and S. Sampath, J. Colloid Interface Sci 2011, 361, 270-27720. https://doi.org/10.1016/j.jcis.2011.05.050

20. T. Jiao, Y. Liu, Y. Wu, Q. Zhang, X. Yan, F. Gao, A. J. Bauer, J. Liu, T. Zeng and B. Li, Sci. Rep 2015, 5, 12451. https://doi.org/10.1038/srep12451

21. S. Park and R. S. Ruoff, Nat. Nanotechnol 2009, 4, 217-224. https://doi.org/10.1038/nnano.2009.58

22. M. J. Allen, V. C. Tung and R. B. Kaner, Chem. Rev 2009, 110, 132-145. https://doi.org/10.1021/cr900070d

23. D. R. Dreyer, S. Park, C. W. Bielawski and R. S. Ruoff, Chem. Soc. Rev 2010, 39, 228-240. https://doi.org/10.1039/B917103G

24. X. Yuan, Y. Wang, J. Wang, C. Zhou, Q. Tang and X. Rao, Chem. Eng. J.2013, 221, 204-213. https://doi.org/10.1016/j.cej.2013.01.090

25. Y.-B. Luo, J.-S. Cheng, Q. Ma, Y.-Q. Feng and J.-H. Li, Anal. Methods2011, 3, 92-98. https://doi.org/10.1039/C0AY00624F

26. R. Kempaiah, S. Salgado, W. L. Chung and V. Maheshwari, Chem. Commun. 2011, 47, 11480-11482. https://doi.org/10.1039/c1cc15096k

27. C. Braun, C. Cook, C. Merritt and J. Rousseau, ORG. SYNTH 1951, 31, 77-79. https://doi.org/10.15227/orgsyn.031.0077

28. L. Janovec, G. Suchár, J. Imrich, P. Kristian, V. Sasinková, J. Alföldi and E. Sedlák, Collect. Czech. Chem. Commun 2002, 67, 665-678. https://doi.org/10.1135/ccce20020665

29. J. Sun, Z. Chen, M. Ge, L. Xu and M. Zhai, J. Hazard. Mater. 2013, 244-245, 94-101. https://doi.org/10.1016/j.jhazmat.2012.11.043

30. M. S. Morey, S. O'Brien, S. Schwarz and G. D. Stucky, Chem. Mater 2000, 12, 898-911. https://doi.org/10.1021/cm9901663

31. C. B. Vidal, A. L. Barros, C. P. Moura, A. C. A. de Lima, F. S. Dias, L. C. G. Vasconcellos, P. B. A. Fechine and R. F. Nascimento, J. Colloid Interface Sci 2011, 357, 466-473. https://doi.org/10.1016/j.jcis.2011.02.013

32. C. Namasivayam and D. Kavitha, Dyes Pigm. 2002, 54, 47-58. https://doi.org/10.1016/S0143-7208(02)00025-6

33. J. Saikia, B. Saha and G. Das, J. Hazard. Mater. 2011, 186, 575-582. https://doi.org/10.1016/j.jhazmat.2010.11.036

34. S. Sun, Y. Cao, J. Feng and P. Wu, J. Mater. Chem. A 2010 , 20, 5605-5607.

35. K. N. Kudin, B. Ozbas, H. C. Schniepp, R. K. Prud'Homme,
I. A. Aksay and R. Car, Nano Lett.2008, 8, 36-41. https://doi.org/10.1021/n1071822y

36. A. Lerf, H. He, M. Forster and J. Klinowski, J. Phys. Chem. B 1998, 102, 4477-4482. https://doi.org/10.1021/jp9731821

37. H.-K. Jeong, Y. P. Lee, R. J. Lahaye, M.-H. Park, K. H. An, I. J. Kim, C.-W. Yang, C. Y. Park, R. S. Ruoff and Y. H. Lee, J. Am. Chem. Soc 2008, 130, 1362-1366.

https://doi.org/10.1021/ja076473o

38. A. Fasolino, J. Los and M. I. Katsnelson, Nat. Mater2007, 6, 858-861. https://doi.org/10.1038/nmat2011

39. O. Glukhova and M. Slepchenkov, Nanoscale. 2012, 4, 3335-3344. https://doi.org/10.1039/c2nr30477e

40. Z. Pei, L. Li, L. Sun, S. Zhang, X.-q. Shan, S. Yang and B. Wen, Carbon. 2013, 51, 156-163. https://doi.org/10.1016/j.carbon.2012.08.024

41. J. Wang, Z. Chen and B. Chen, Environ. Sci. Technol 2014, 48, 4817-4825. https://doi.org/10.1021/es405227u

42. L. N. Z. X.G. Luo, J. Hazard. Mater 2009, 171, 340-347. https://doi.org/10.1016/j.jhazmat.2009.06.009

43. X. Luo, C. Wang, L. Wang, F. Deng, S. Luo, X. Tu and C. Au, Chem. Eng. J.2013, 220, 98-106. https://doi.org/10.1016/j.cej.2013.01.017

44. A. Balati, A. Shahbazi, M. M. Amini and S. H. Hashemi, J water reuse desal. 2015, 5, 50-63.

45. C. B. Vidal, A. L. Barros, C. P. Moura, A. C. De Lima, F. S. Dias, L. C. Vasconcellos, P. B. Fechine and R. F. Nascimento, J. Colloid Interface Sci 2011, 357, 466-473. https://doi.org/10.1016/j.jcis.2011.02.013

46. S. Yakout, A. Daifullah and S. El-Reefy, Adsorp. Sci. \& Technol.2013, 31, 293-302. https://doi.org/10.1260/0263-6174.31.4.293

47. C. Zhang, X. Zhang, Z. Huang, D. Huang and Q. Cheng, $J$ Environ Anal Toxicol 2012, 2012.

48. J. Zhao, Z. Wang, Q. Zhao and B. Xing, Environ. Sci. Technol 2013, 48, 331-339.

https://doi.org/10.1021/es403873r

49. K. Yang, L. Zhu and B. Xing, Environ. Sci. Technol 2006, 40, 1855-1861. https://doi.org/10.1021/es052208w

50. T. H. Nguyen, H.-H. Cho, D. L. Poster and W. P. Ball, Environ. Sci. Technol 2007, 41, 1212-1217.

https://doi.org/10.1021/es0617845

51. X. Cheng, A. T. Kan and M. B. Tomson, J. Chem. Eng. Data 2004, 49, 675-683. https://doi.org/10.1021/je030247m

52. B. Cabal, C. O. Ania, J. B. Parra and J. Pis, Chemosphere. 2009, 76, 433-438. https://doi.org/10.1016/j.chemosphere.2009.04.002

53. C.-F. Chang, C.-Y. Chang, K.-H. Chen, W.-T. Tsai, J.-L. Shie and Y.-H. Chen, J. Colloid Interface Sci 2004, 277, 29-34. https://doi.org/10.1016/j.jcis.2004.04.022

54. B. Pan, D. Lin, H. Mashayekhi and B. Xing, Environ. Sci. Technol 2008, 42, 5480-5485. https://doi.org/10.1021/es8001184

55. P. Lazar, F. Karlický, P. Jurečka, M. Kocman, E. Otyepková, K. Šafár̆ová and M. Otyepka, J. Am. Chem. Soc 2013, 135, 
6372-6377. https://doi.org/10.1021/ja403162r

56. B. X. D. Lin, Environ. Sci. Technol 2008, 42, 7254-7259. https://doi.org/10.1021/es801297u

57. M. S. I. Efremenko, Langmuir. 2006, 22, 3614-3621. https://doi.org/10.1021/la052100u

58. X. W. K. Yang, L. Zhu, B. Xing, Environ. Sci. Technol 2006, 40, 5804-5810. https://doi.org/10.1021/es061081n

59. W. W. K. Yang, Q. Jing, L. Zhu, Environ. Sci. Technol 2008, 42, 7931-7936. https://doi.org/10.1021/es801463v

60. J. J. P. M. Sander, Environ. Sci. Technol 2005, 39, 1606-
1615. https://doi.org/10.1021/es0491351

61. F.-G. Klärner and T. Schrader, Acc. Chem. Res 2012, 46, 967-978.

62. M. Hardouin-Lerouge, P. Hudhomme and M. Sallé, Chem. Soc. Rev 2011, 40, 30-43. https://doi.org/10.1039/B915145C

63. J. Leblond and A. Petitjean, ChemPhysChem 2011, 12, 1043-1051. https://doi.org/10.1002/cphc.201001050

64. C. Chen and H. Whitlock Jr, J. Am. Chem. Soc 1978, 100, 4921-4922. https://doi.org/10.1021/ja00483a063

\section{Povzetek}

Modificiran grafenov oksid smo pripravili z namenom njegove uporabe kot odstranjevalca aromatskih onesnaževalcev iz vodnih raztopin. Grafenov oksid (GO) smo funkcionalizirali z 9-aminoantracenom in pripravili grafenov oksid 9aminoantracen (GO-9-AA). Za karakterizacijo adsorbenta smo uporabili naslednje metode: infrardečo spektroskopijo (FTIR), rentgensko praškovno difrakcijo (XRD), termogravimetrično analizo (TGA), transmisijsko elektronsko mikroskopijo (TEM in ramansko spektroskopijo. Kot modelne aromatske ogljikovodike, primerne za preučevanje adsorpcije, smo uporabili naftalen (NAP), acenaftalen (ACN) in fenantren (PHN). Adsorbent GO-9-AA je bil zelo učinkovit v primeru odstranjevanja aromatskih ogljikovodikov iz vodnih raztopin. Ravnotežni podatki adsorpcijskih procesov sledijo Freundlichovemu modelu, maksimalne adsorpcijske kapacitete za preučevane aromatske ogljikovodike pa lahko podamo z zaporedjem NAP > ACN > PHN. Iz podatkov kinetične analize lahko razberemo, da je proces hiter in učinkovit in ustreza kinetičnemu modelu psevdo-drugega reda. Obroči antracena na grafenovem oksidu (GO-9-AA) so »bogati« s $\pi$ elektroni in zaradi tega pospešujejo interakcijo le-tega z aromatskimi ogljikovodiki (NAP, ACN in PHN). 